\title{
Primary health center approach for oral health related knowledge, attitude and practice among primary health care workers of western India
}

\begin{abstract}
Background: Health care workers form an important component of the health care system of any nation, they should have adequate knowledge about oral health as it directly affect the general health, of the people this study was carried out to assess knowledge, attitude, and practices among primary health care workers in Jaipur.
\end{abstract}

Materials \& methods: This cross-sectional study was conducted among 220 Primary Health care workers present on the day of the survey. Among 220 samples $130 \& 90$ health workers were included from Jaipur-I CHMO and Jaipur-II CHMO respectively. Statistical analysis was done using descriptive frequency and chi-square test.

Results: A majority of the primary health care workers had moderate oral health knowledge level. Anganwadi workers had the least knowledge followed by ASHA (Accredited social health activist) worker, Auxiliary nursing midwifery (ANM) and GNM (General nursing mid wifery). The majority of study subjects have heard about pyorrhea $(84.09 \%)$ and tooth decay $(84.09 \%)$ while nearly half of the study subjects $(56.8 \%$ and $50.4 \%)$ have heard about irregular teeth and oral cancer respectively. Sixty nine point five percent study subjects use toothbrush and toothpaste for cleaning their teeth. More than half of subjects $(59.5 \%)$ brush their teeth once a day while $36.3 \%$ subjects brush twice daily.

Conclusion: Oral health training should be given to primary health workers so that they can educate village people and make them aware at the oral health problems.

Keywords: knowledge, attitude, practice, oral health, health worker, dental caries, education
Volume 5 Issue 3 - 2016

\author{
Kaluram Yadav,' Jitender Solanki,' Adyanthaya \\ BR, ${ }^{2}$ Omprakash Yadav,' Girish R Shavi, ${ }^{3}$ \\ Priyanka Yadav' \\ 'Department of Public Health Dentistry, Rajasthan Dental \\ College \& Hospital Jaipur, India \\ ${ }^{2}$ Department of Conservative and Endodontics Rajasthan \\ Dental College \& Hospital Jaipur, India \\ ${ }^{3}$ Department of Public Health Dentistry, Rama Dental College \\ \& Hospital, India
}

Correspondence: Kaluram Yadav, Department of Public Health Dentistry, Rajasthan Dental College \& Hospital Jaipur, India, Tel +919829299668, Email kaluram 1688@gmail.com

Received: August 27, 2016| Published: October 17, 2016

\section{Introduction}

Health is a state of complete physical, mental and social well being, and not merely absence of disease or infirmity. ${ }^{1}$ It is one of the most essential aspects that one possesses. Oral health, which is an integral part of general health, may be defined as "standard of health of the oral and related tissues which enables an individual to eat, speak and socialize without active disease, discomfort or embarrassment and which contributes to general well-being". ${ }^{2}$ Oral diseases are categorized as chronic non-communicable diseases. Analysis of current data suggests that $80 \%$ of the population of the world is affected by dental caries and periodontal disease. In our country, dental caries is seen in $80-90 \%$ of children of 16 years of age and the average DMFT of 4 , similarly $95-100 \%$ of the population is affected by periodontal diseases. ${ }^{3}$ As on March 2012, there were 23887 Primary Health Centers (PHCs), 148124 Sub Centers and 4809 Community Health Centers (CHCs) functioning in India. ${ }^{4}$ Primary Health Care Workers (HCWs) are the first people of health sector who come in contact with general population. They are the people who closely monitor the conditions and disease pattern among the people. It is very important for them to have knowledge about oral diseases and how to prevent them, so that they can help the people to adopt healthy oral health practices. Oral disease put on a heavy burden on the disease pattern worldwide and the current data suggests that $80 \%$ of the population around the globe is affected by dental caries or periodontal disease. In India, dental caries is seen in $70-80 \%$ of population with the average DMFT of 4 , similarly $85 \%$ of the people are affected by periodontal diseases. ${ }^{3}$ For the primary health care workers to spread messages related to oral health, they must have adequate knowledge about the etiology, epidemiology, treatment and prevention of oral diseases. ${ }^{5}$ After exploration the available literature it was observed that no study is conducted on the primary health care workers and their knowledge, attitudes and practices toward oral health. Keeping this in consideration the present study was undertaken with the aim to assess Knowledge, Attitude and Practice regarding oral health among primary health care workers of Jaipur district.

\section{Materials and methods}

Jaipur district is divided in two chief medical and health office zones (CMHO). Two community health centres (CHC's) from each $\mathrm{CHMO}$ zones and from these CHC's two primary health centres (PHC's) were randomly selected. The list of Community Health Centers (CHC's) and Primary Health Centre (PHC's) was obtained from Ministry of health, Rajasthan state. The present cross-sectional questionnaire based study was conducted among Primary Health care workers of Jaipur district. Health workers working at PHC's such as Auxiliary nursing midwifery (ANM's), General nursing midwifery (GNM's), ASHA and Aganwadi workers were the target populations. Ethical clearance was obtained from the concerned 
authorities. Informed and verbal consent was taken from each subject. Confidentiality of the respondents' was maintained throughout the study. The study proforma consisted of questions about general information and a self-designed and pre-tested close ended 22 item questionnaire to assess Knowledge, Attitude and Practice about oral health. The proforma was made in regional language (Hindi). All the primary health care workers were given prior information about the day and date of the study, the health workers present on the day and if interested was included in the study. The examiner visited a maximum of two primary health centers on the scheduled days and collected the required data. The questionnaire was distributed and in case of any doubts clarifications were made by the examiner. Data thus collected was entered in the Microsoft Excel and frequency distribution, chisquare test were applied for data analysis using SPSS software version 20.00

\section{Results}

The present cross-sectional study was conducted among 220 health care workers of primary health centre and sub centers of Jaipur district. Out of 220 study subjects 110 were (ASHA Worker), 75 (Aganwadi worker), 26(ANM's) and 9 (nursing staff). It was observed that $60.9 \%$ of study subjects knew about total number of permanent and deciduous teeth in the oral cavity. Out of which $53.4 \%, 60 \%, 84.6 \%$ and $88.8 \%$ were ASHA, Aganwadi worker, ANM and nursing staff had the knowledge respectively (Table 1). Sixty six point eighty two percent of subjects knew when the first tooth erupts in the oral cavity out of which $68.1 \%, 62.6 \%, 73 \%$ and $66.6 \%$ ASHA, aganwadi worker, ANM, and nursing staff respectively knew about it. Sixty eight point six percent of the subjects had knowledge regarding to stop feeding by bottles in children out of which highest knowledge was seen among Nursing staff (88.8\%) and ANM's (84.6\%). Knowledge regarding effects of thumb sucking on teeth were found highest among nursing staff (100\%), followed by $92.3 \%, 63.3 \%$, and 54.6\% ANM's, ASHA and Aganwadi workers respectively. When Knowledge regarding effects of nail biting on teeth was assessed ANM'S (66.9\%), followed by $66.6 \%, 57.2 \%$, and $48 \%$ nursing staff, ASHA and Aganwadi workers respectively. Seventy three point one percent of the study subjects knew that television and radio are the main source of oral health knowledge while only $21.3 \%$ subjects thought that dentist can also be a source of regarding oral health knowledge. The majority of study subjects have heard about pyorrhea $(84.09 \%)$ and tooth decay $(84.09 \%)$ while nearly half of the study subjects $(56.8 \%$ and $50.4 \%)$ have heard about irregular teeth and oral cancer respectively. Eighty five percent of the study subjects knew that excess intake of sweet can cause tooth decay. Eighty seven point seven percent of the subjects replied that tooth brushing can reduce the tooth decay (Table 1). Nearly half of the study subjects $(51.8 \%)$ knew that children should start brushing at the age of 3-5 years. Majority of subjects knew that dental treatment was equally important as medical. Eighty one point three study subjects discussed regarding oral health with children, among them $100 \%, 92.3 \%, 84.5 \%$ and $70.6 \%$ nursing staff, ANM's, ASHA and Aaganwadi worker discuss respectively. Seventy six point eight percent of the study subjects had visited dentist for their dental problems, while $6.8 \%$ subjects had visited ayurvedic hospital for the treatment. Seventy eight point one percent of the subjects knew those regular dental checkups are necessary for good oral health. Sixty nine point five percent study subjects use toothbrush and toothpaste for cleaning their teeth. More than half of subjects $(59.5 \%)$ brush their teeth once a day while $36.3 \%$ subjects brush twice daily. Thirty seven point seven percent subjects took 1-2 minutes for tooth brushing and $68.6 \%$ of the study subjects rinse their mouth with plain water after every meal. Forty nine percent subjects eat sweet once day while $36.6 \%$ study subjects ate sweet 2-4 times a day. Nearly half of the subjects $(54 \%)$ get their dental checkup regularly while only $35 \%$ of the study subjects had visited dentist only for dental pain (Table 2).

Table I Oral health related knowledge among health care workers

\begin{tabular}{|c|c|c|c|c|c|c|c|}
\hline \multirow{2}{*}{$\begin{array}{l}\text { How many deciduous and } \\
\text { permanent teeth are present in } \\
\text { our mouth? }\end{array}$} & $N(220)$ & ASHA (II0) & AWW (75) & ANM (26) & Nursing Staff (9) & $\mathbf{X}^{2}$ & 'p' Value \\
\hline & No. (\%) & No. (\%) & No. (\%) & No. (\%) & \multicolumn{3}{|l|}{ No. (\%) } \\
\hline 20 deciduous and 32 permanent & $134(60.91)$ & $59(53.64)$ & $45(60)$ & $22(84.6)$ & $8(88.89)$ & \multirow[t]{5}{*}{21.65} & \multirow[t]{5}{*}{$0.042 *$} \\
\hline 20 deciduous and 30 permanent & $29(13.18)$ & $15(13.64)$ & $13(17.33)$ & I (3.85) & $0(0)$ & & \\
\hline 10 deciduous and 32 permanent & $31(14.09)$ & $17(15.45)$ & II (I4.67) & $2(7.69)$ & $I(I I . I I)$ & & \\
\hline 16 deciduous and 28 permanent & $24(10.01)$ & $19(17.27)$ & $4(5.3)$ & $\mathrm{I}(3.85)$ & $0(0)$ & & \\
\hline Don't know & $2(0.91)$ & $0(0)$ & $2(2.67)$ & $0(0)$ & $0(0)$ & & \\
\hline \multicolumn{8}{|c|}{ At what age first deciduous teeth erupts in mouth? } \\
\hline 6-7 months & $147(66.82)$ & $75(68.18)$ & $47(62.67)$ & $19(73)$ & $6(66.67)$ & \multirow[t]{5}{*}{3.56} & \multirow[t]{5}{*}{0.99} \\
\hline 8-9 months & $68(30.91)$ & $33(30)$ & $25(33.33)$ & $7(26.92)$ & $3(33.33)$ & & \\
\hline I0-II months & I $(0.45)$ & $0(0)$ & $\mathrm{I}(\mathrm{I} .33)$ & $0(0)$ & $0(0)$ & & \\
\hline $12-13$ months & $2(0.91)$ & I (0.9I) & I ( $(1.33)$ & $0(0)$ & $0(0)$ & & \\
\hline Don't know & $2(0.91)$ & I (0.9I) & $\mathrm{I}(\mathrm{I} .33)$ & $0(0)$ & $0(0)$ & & \\
\hline \multicolumn{8}{|c|}{ Have you heard about any of these diseases of mouth? } \\
\hline Pyorrhea & $185(84.09)$ & $89(80.91)$ & $62(82.67)$ & $25(96.1)$ & $9(100)$ & \multirow[t]{5}{*}{5.47} & \multirow[t]{5}{*}{0.185} \\
\hline Tooth decay & I85 (84.09) & $96(87.27)$ & $58(77.33)$ & $23(88.5)$ & $8(88.8)$ & & \\
\hline Irregular teeth & I 25 (56.82) & $72(65.45)$ & $3 I(4 I .33)$ & $16(61.5)$ & $6(66.6)$ & & \\
\hline Oral cancer & I I I (50.45) & 49 (44.55) & $43(57.33)$ & I I (42.3) & $8(88.8)$ & & \\
\hline Not heard & $2(0.91)$ & $0(0)$ & $2(2.67)$ & $0(0)$ & $0(0)$ & & \\
\hline
\end{tabular}


Table continued...

\begin{tabular}{|c|c|c|c|c|c|c|c|}
\hline \multirow{2}{*}{$\begin{array}{l}\text { How many deciduous and } \\
\text { permanent teeth are present in } \\
\text { our mouth? }\end{array}$} & $\mathbf{N}(220)$ & ASHA ( 110$)$ & AWW (75) & ANM (26) & Nursing Staff (9) & $\mathbf{X}^{2}$ & 'p'Value \\
\hline & No. (\%) & No. (\%) & No. (\%) & No. (\%) & No. (\%) & & \\
\hline \multicolumn{8}{|c|}{ Do you think high sweet intake can cause tooth decay? } \\
\hline Yes & $187(85)$ & $93(84.55)$ & $6 I(81.33)$ & $24(92.3)$ & $9(100)$ & 4.83 & 0.566 \\
\hline No & $22(10)$ & $12(10.91)$ & $8(10.67)$ & $2(7.69)$ & $0(0)$ & & \\
\hline Don't know & II (5) & $5(4.5)$ & $6(8)$ & $0(0)$ & $0(0)$ & & \\
\hline \multicolumn{8}{|c|}{ Do you think tooth brushing can reduce the chances of tooth decay? } \\
\hline Yes & 193(87.73) & $97(88.2)$ & $61(81.33)$ & $26(100)$ & $9(100)$ & 11.42 & 0.076 \\
\hline No & $12(5.45)$ & $8(7.27)$ & $4(5.33)$ & $0(0)$ & $0(0)$ & & \\
\hline Don't know & $15(6.82)$ & $5(4.55)$ & $10(13.33)$ & $0(0)$ & $0(0)$ & & \\
\hline
\end{tabular}

$*$ Significant $(\mathrm{p}<0.5)$

ASHA, accredited social health activist;AWW, aganwadi workers; ANM, auxiliary nursing midwifery; $\mathrm{X}^{2}$, chi square

Table 2 Oral health related attitude and practice among health care workers

\begin{tabular}{|c|c|c|c|c|c|c|c|}
\hline \multirow{2}{*}{$\begin{array}{l}\text { What are you using for cleaning } \\
\text { of your teeth? }\end{array}$} & $\mathbf{N}(220)$ & ASHA (I I0) & AWW (75) & ANM (26) & Nursing Staff (9) & $\mathbf{X}^{2}$ & 'p' Value \\
\hline & No. (\%) & No. (\%) & No. (\%) & No. (\%) & No. (\%) & & \\
\hline Tooth brush and tooth paste & $153(69.55)$ & $73(66.36)$ & $50(66.67)$ & $21(80.77)$ & $9(100.0)$ & 6.3 & $0.128 *$ \\
\hline Tooth powder & $48(2 \mid .82)$ & $31(28.18)$ & $13(17.33)$ & $3(11.54)$ & $0(0.00)$ & & \\
\hline Datoon & $24(10.91)$ & $9(8.18)$ & $13(17.33)$ & $2(7.69)$ & $0(0.00)$ & & \\
\hline Any other product & $4(1.82)$ & $0(0.00)$ & $4(5.33)$ & $0(0.00)$ & $0(0.00)$ & & \\
\hline \multicolumn{8}{|c|}{ How many times do you brush in day? } \\
\hline Once a day & | 31 |(59.55) & $68(61.82)$ & $4 \mathrm{I}(54.67)$ & $16(61.54)$ & $6(66.67)$ & 9.56 & 0.393 \\
\hline Twice a day & $80(36.36)$ & $35(61.82)$ & $32(42.67)$ & $10(38.46)$ & $3(33.33)$ & & \\
\hline More than two & $6(2.73)$ & $6(5.45)$ & $0(0.00)$ & $0(0.00)$ & $0(0.00)$ & & \\
\hline Never & $3(1.36)$ & $\mathrm{I}(0.9 \mathrm{I})$ & $2(2.67)$ & $0(0.00)$ & $0(0.00)$ & & \\
\hline \multicolumn{8}{|c|}{ For how much time do you brush your teeth } \\
\hline Less than I minute & $75(34.09)$ & $44(40)$ & $22(29.33)$ & $72(6.92)$ & $2(22.22)$ & 8.73 & 0.472 \\
\hline I-2 minute & $83(37.73)$ & $33(30)$ & $33(44)$ & $\mathrm{II}(42.3 \mathrm{I})$ & $6(66.67)$ & & \\
\hline More than 3 minute & $60(27.27)$ & $33(30)$ & $20(26.66)$ & $8(30.77)$ & $\mathrm{I}(\mathrm{II} . \mathrm{II})$ & & \\
\hline \multicolumn{8}{|c|}{ Do you rinse your mouth after every meal? } \\
\hline Yes & I5I(68.64) & $75(68.18)$ & $45(60.00)$ & $22(84.62)$ & $9(100)$ & 16.51 & 0.057 \\
\hline No & $29(13.18)$ & $18(16.36)$ & $8(10.67)$ & $3(11.54)$ & $0(0.00)$ & & \\
\hline Occasionally & $37(16.82)$ & $15(13.64)$ & $2 I(28.00)$ & $\mathrm{I}(3.85)$ & $0(0.00)$ & & \\
\hline Never & $3(1.36)$ & $2(1.82)$ & $\mathrm{I}(\mathrm{I} .33)$ & $0(0.00)$ & $0(0.00)$ & & \\
\hline \multicolumn{8}{|c|}{ When do you visit a dentist for dental checkup? } \\
\hline Regularly & $119(54.09)$ & $65(59.09)$ & $40(53.33)$ & $13(50.00)$ & $\mathrm{I}(\mathrm{II} . \mathrm{II})$ & 7.99 & 0.06 \\
\hline Only on tooth pain & $77(35.00)$ & $36(32.73)$ & $28(37.33)$ & $9(34.62)$ & $4(4.44)$ & & \\
\hline Occasionally & $24(10.91)$ & $9(8.18)$ & $7(9.33)$ & $4(15.38)$ & $4(4.44)$ & & \\
\hline Never & $8(3.64)$ & $3(2.73)$ & $5(6.67)$ & $0(0.00)$ & $0(0.00)$ & & \\
\hline
\end{tabular}

$*=$ Significant $(\mathrm{p}<0.5)$

ASHA, accredited social health activist;AWW, aganwadi workers;ANM, auxiliary nursing midwifery; $\mathrm{X}^{2}$, chi square 


\section{Discussion}

The dedicated health care worker $(\mathrm{HCW})$ is the most important person in the health system $\mathrm{HCW}$ plays very important role in the proper functioning and stability of the health system in rural areas. HCW carry a tremendous responsibility to assist and provide the best possible health facilities that are in his limits. The impact of oral disease on One's life is subtle and pervasive, influencing eating, sleeping, work and social roles. ${ }^{6}$ The present study was designed with the sole purpose of assess the knowledge, attitude, and practices of primary health care workers belonging to one of the districts in the northwest part of the India. The primary health care workers were chosen because they have a relatively easy access to rural population and can deliver health services to the people residing in the rural areas on the country. More than $80 \%$ of the ANM's, Nursing staff had knowledge about total number of primary and permanent teeth. Only half of the Anganwadi and ASHA workers had knowledge about total number of primary and permanent teeth. About $80 \%$ of the health workers had knowledge about pyorrhea and dental caries. This result is in close agreement $(88.5 \%)$ with the study done by Amuh VO et al., ${ }^{7}$ while the results of study done by Bhoopathi PH et al., 5 showed that only $40 \%$ people had knowledge, which do not match with present study. In present study more than $80 \%$ of the nursing staff had knowledge about oral cancer whereas only half of the other health workers had knowledge about oral cancer. In a Study done by Chanchal Gangwar et al., ${ }^{8}$ only $40 \%$ health workers had knowledge about tobacco causes oral cancer. Study done by Sood P et al., ${ }^{9}$ contradicted this statement in which majority of the subjects $(80 \%)$ had knowledge that tobacco causes oral cancer. More than $80 \%$ of the health workers had knowledge that sugar causes dental caries which is contradicted by the study done by Aggnur et al., ${ }^{10}$ in which they showed that $62.2 \%$ HCW's knew that sugar causes dental caries respectively. In the present study more than $70 \%$ of all health care workers discussed oral health with children and asked them to visit a dentist for dental problems. Thirty five percent and fifty four percent HCW's had visited a dentist in case of pain and regular visit respectively, while in a study conducted by Chanchal Gangwar et al., ${ }^{8}$ nearly half of subjects $(53.6 \%)$ had visited dentist during pain and only $(0.2 \%)$ visited regularly. In present study more than $69.55 \%$ of health care workers use toothbrush and toothpaste for cleaning their teeth and $59.55 \%$ and $36.4 \%$ of subjects brush their teeth once and twice daily respectively. It is in close agreement with the study conducted by Gangwar et al., ${ }^{8}$ in which $68 \%$ of the respondents brushed once per day and $32 \%$ of the respondents brushed their teeth twice per day respectively.

\section{Conclusion}

There is an adequate knowledge of dental care, but poor oral hygiene practices among the health workers. Knowledge about oral health is very important so as to correct their improper practices is therefore highly recommended. It is necessary to include subject of oral health in curricular of medical school so that more emphasis can be pad on to oral health promotion and preventive aspects as well as community participation.

\section{Recommendations}

In view of the findings of the present study, it is recommended that: a. Routine oral checkup of all the health workers should be made at their respective health care centers.

b. Knowledge about oral should be given to all the health workers so as to enhance their awareness, knowledge and practices

c. Importance of oral health should be included in the education of the health workers so that it is part of their education

d. There is an urgent need for further studies and research in this area as very limited previous data is available.

\section{Funding}

None.

\section{Acknowledgments}

None.

\section{Conflicts of interest}

Authors declare that there is no conflict of interest.

\section{References}

1. Park K. Park's Textbook of Preventive and Social Medicine. 23rd ed. Banarsidas Bhanot Publishers: Jabalpur, India; 2015.

2. Lal S, Paul D, Vashisht BM. Oral Health in America: A Report of the Surgeon General. Rockville, MD: US Department of Health and Human Services, National Institute of Dental and Craniofacial Research, National Institutes of Health; 2004.

3. Sunder Lal, Dinesh, Vashisht. National Oral Health Care Programme (NOHCP) implementation strategies. Indian $J$ Community Med. 2004;29(1):3.

4. Simon AK, Ashwini R, Rajesh G, et al. Oral Health Care Availability in Health Centers of Mangalore Taluk, India. Indian $J$ Community Med. 2014;39(4):218-222.

5. Praveen HB, Reddy P Arpitha K, et al. Oral health related knowledge, attitude and practices among the primary health care workers of a district in India. J Int Soc Prev Community Dent. 2014;4(Suppl 1):S11-S17.

6. Outcomes and impact of oral disease Report of the national advisory council on dental health. Department of health, Australian government; 2012 .

7. Amuh VO, Okojie OH, Ehizele. Dental Care Knowledge and Practice of a Group of Health Workers in Benin City, Nigeria. Ann Med Health Sci Res. 2014;4(Suppl 3):S307-S310.

8. Chanchal Gangwar, Manish Kumar, Nagesh L. KAP toward Oral Health, Oral Hygiene and Dental Caries Status among Anganwadi Workers in Bareilly City, Uttar Pradesh: A Cross-Sectional Survey. Journal of Dental Sciences and Oral Rehabilitation. 2014;5(2):53-57.

9. Poonam Sood, Ridhi Narang, Swathi, et al. Dental patient's knowledge and perceptions about the effects of smoking and role of dentists in smoking cessation activities. Eur J Dent. 2014;8(2):216-223.

10. Aggnur M, Garg, Veeresha, et al. Oral Health Status, Treatment Needs and Knowledge, Attitude and Practice of Health Care Workers of Ambala, India A Crosssectional Study. Ann Med Health Sci Res. 2014;4(5):676-681. 